\title{
O professor de filosofia: limites e possibilidades - dinâmica e problematização do ensino-aprendizagem
}

\author{
Anderson Magno da Silva Pimentel \\ Dawson de Barros Monteiro \\ Escola Estadual Professora Amélia Coelho
}

\section{Resumo}

A temática do presente texto versa sobre limites e possibilidades do professor de filosofia na relação ensino-aprendizagem desenvolvida nas salas de aula. Localizando os elementos fundamentais ao processo pedagógico - tais como o ensino, o papel do professor, a experiência filosófica e o sentido pedagógico de reaprender o aprendido -, o contexto pedagógico é pensado nos seus agentes e no objetivo a ser alcançado: o conhecimento que permite a integração de saberes. Recorrendo à contribuição do pensamento de Hannah Arendt no que corresponde ao esclarecimento de uma das várias questões da crise da educação, que segundo a autora é a quebra da autoridade do professor, faz-se o resgate do papel fundamental do docente no jogo ensino-aprendizagem. Tal resgate torna-se possível quando a prática docente é repensada nos termos próprios de sua fundamentação e perspectiva mais abrangente: a formação humana. Ao longo do texto, as propostas pedagógicas de pensadores da educação para o ensino de filosofia em turmas de ensino médio contribuem para a compreensão das perspectivas lançadas na abordagem do tema. Elementos como aprendizagem, conteúdo, ensino, processo educativo são retomados de modo que favoreçam a apreensão do sentido verdadeiramente filosófico da disciplina filosofia. Imprescindivel para tal acontecimento é a experiência, que não se caracteriza empiricamente, mas no modo pela qual busca contribuir para o desenvolvimento do modo de conceber e desenvolver a docência de filosofia, da mesma forma que tem por intenção permitir o florescimento de novas formas de aprendizagem como proporcionadora de uma verdadeira experiência filosófica.

\section{Palavras-chave}

Limites - Possibilidades - Filosofia - Ensino-aprendizagem.

Correspondência:

Dawson de Barros Monteiro

Rua Eugênio Cunha, 31 - Cajá

55610-210 - Vitória de Santo Antão - PE

E-mail: dawson_810@hotmail.com 


\title{
The philosophy teacher: limits and possibilities - dynamics and problematization of teaching-learning
}

\author{
Anderson Magno da Silva Pimentel \\ Dawson de Barros Monteiro \\ Escola Estadual Professora Amélia Coelho
}

\begin{abstract}
The theme of this text is the limits and possibilities of the philosophy teacher in the teaching-learning relation established in the classroom. Locating the fundamental elements of the pedagogical process - such as the teaching, the role of the teacher, the philosophical experience, and the pedagogical meaning of re-learning what has been learned, the pedagogical context is reflected upon through its agents and through the objective in sight: the knowledge that allows the integration of knowledges. Drawing on the contribution of Hannah Arendt's thinking related to the clarification of one of the many issues in the crisis of education, which, according to the author is the collapse of the teacher's authority, the text recovers the fundamental role of the teacher in the teaching-learning game. Such recovery becomes possible when the teaching practice is rethought in the terms of its own grounding, and under its wider perspective: human formation. Along the text the pedagogical proposals of education thinkers as related to the teaching of philosophy to secondary education classes contribute to the understanding of the perspectives put forward in dealing with this issue. Elements such as learning, content, teaching and educational process are resumed in such a way as to help apprehending the truly philosophical meaning of the philosophy discipline. Crucial to this achievement is experience, which is not empirically characterized, but is conceived in the way its searches to contribute to the development of the form of understanding and developing the teaching of philosophy, and equally in its intention to allow the flourishing of new ways of learning as affording a truly philosophical experience.
\end{abstract}

\section{Keywords}

Limits - Possibilities - Philosophy - Teaching-learning.

Contact:

Dawson de Barros Monteiro

Rua Eugênio Cunha, 31 - Cajá

55610-210 - Vitória de Santo Antão - PE

E-mail: dawson_810@hotmail.com 
A análise sobre a questão do ensino de filosofia incide sobre três pontos elementares: o objetivo e o teor do ensino-aprendizagem de filosofia, a quem este é dirigido e quem o protagoniza, no caso, o professor de filosofia. 0 ponto de partida é caracterizar os envolvidos diretos na educação quando estes estão na sala de aula. Presume-se, seguindo a perspectiva do pensamento pedagógico de Libâneo (1985), “a interligação que há no ato pedagógico entre três componentes: um agente, uma mensagem transmitida, um educando" (p. 95, grifos nosso). A temática do presente texto versa sobre os possíveis limites e as possibilidades do professor de filosofia na relação ensino-aprendizagem desenvolvida nas salas de aula.

0 caráter de uma pesquisa é que possa reunir elementos que lhe dê fundamentação e que da mesma forma seja um referencial no aprofundamento, sempre mais sistemático, da questão investigada. Dessa forma, a pesquisa tem, por si mesma, uma inesgotabilidade, pois se estabelecida como determinação ou ponto de chegada que encerra o perscrutar, o que dela restaria a não ser um amontoado de folhas?

A pesquisa, então, é um elemento a favor do pesquisador, pois the viabiliza a difusão do conhecimento. É também favorável à construção do saber referente a um determinado assunto, expressando a dinamicidade e o rigor com que deve ser regida, caso contrário seu caráter epistemológico pode ser seriamente comprometido.

A interpretação que aqui foi dada ao tema se encaminha por uma abordagem hermenêuticofenomenológica. 0 homem é um ser no mundo e nele se faz e age, daí, suas ações, por serem intencionais, podem ser interpretadas de um ponto de vista político, como ações que visam decididamente sobre a forma de ser-no-mundo. A leitura de Hannah Arendt (2005) sobre os fatos humanos tende a encaminhar o leitor de sua obra à interpretação desses fatos como caracteristicamente ações políticas que incidem diretamente sobre o homem e na sua forma de agir.

Interpretar os fenômenos humanos não deixa de ser uma compreensão dos fatos como também das possibilidades que se abrem no horizonte da ação humana. A metodologia que, privilegiada, não busca, em si mesma, encerrar o que pode ser dito sobre o professor de filosofia nos seus limites e possibilidades. Antes, deseja indicar possiveis elementos que prescindem da atuação humana localizada e pontuada em termos de ensino. Um dos pontos que norteia a presente reflexão é a possibilidade de melhor compreensão quanto à irrupção do novo por meio da prática educativa:

A educação não é a simples transmissão da herança dos antepassados para as novas gerações, mas o processo pelo qual se torna possível a gestação do novo e a ruptura com o velho. (Aranha, 2007, p. 31)

Nessa análise, a pontuação das questões se focaliza no espaço escolar como campo de atuação, pesquisa e conhecimento, enfatizando a atuação do professor de filosofia no exercício de sua docência. A escola como instituição social', de moldes caracteristicamente modernos, corresponde ao projeto da llustração, que asseverou o homem na busca pelo saber, estabelecendo um marco indelével ao nosso tempo: o da subjetividade. A Modernidade, ao tomar em consideração a célebre frase de Aristóteles no início da Metafísica - "todos os homens, naturalmente, desejam conhecer" -, levou-a ao máximo de sua afirmação. A exemplo de ilustração: a Teoria do Conhecimento foi tematizada e firmada de tal modo como campo de conhecimento e posteriormente como disciplina. Daí constituiu-se como um dos campos de investigação e interpretação sobre o conhecimento humano dentro do conjunto filosófico de disciplinas.

A presença da instituição escola, nos variados espaços socioculturais e no imaginá-

1. "Significa falar do espaço educativo escolar como veículo de construção e transmissão de um saber científico, universal, cultural, com divisões de mundo e de um ensino de boa qualidade, enfim, 'que propicie a formação integral da personalidade dos indivíduos enquanto sujeitos da história'”. (Saviani apud Silva, 2004, p. 34). 
rio social, revela-se como um fenômeno de características próprias e objetividade definida. À escola, que corresponde a uma função, mesmo que hoje esta esteja obscurecida ao entendimento geral, esta funcionalidade não deixou de existir. É possível perceber certo distanciamento entre a dinâmica da comunidade escolar e o conjunto social como um todo, geralmente no que se refere à escola pública como nos lembra Saviani (apud Silva, 2004).

Não vamos tratar especificamente da função da escola. A colocação do termo no singular pontua o que se atribui como sua função social: a de educar para a emancipação cultural dos indivíduos, conforme pensou a Modernidade. Contudo, muitas outras abordagens poderiam ser assumidas no que toca a essa funcionalidade. Poderíamos, sem medo de errar, conceituar como funções da escola, afinal "a pluralidade de interpretações que o fenômeno escolar abarca permite um alargamento conceitual como também abarcaria uma rica diversidade de interpretações" (Silva, 2004, p. 43). 0 objetivo que permeia a reflexão aqui exposta é de pensar algumas tensões que marcam a atividade do docente no que e quando se propõe a lecionar filosofia.

0 perfil do professor, as possibilidades e o 'como"2 ensinar filosofia e o próprio ensino filosófico como vetor de reflexão são, por si mesmo, elementos cuja fundamentação deve ser sempre pensada tendo em vista a quem está sendo dirigido.

Para evitar equívocos quanto à colocação do termo como, o que se pretende não é estabelecer um cronograma de atividades que necessariamente tenham que ser desenvolvidas em sala de aula, mas, concernente à metodologia abordada, o que se pensa é refletir a interpretação que se possa dar ao fenômeno do ensino na fundamentação de sua característica de fazer compreender o que pode ser inteligível. Em outros termos, é discutir a maneira de se abordar a ensinabilidade própria da filosofia na ação do docente em sala de aula. 0 como diz respeito ao fenômeno de ensinar e sua mais esperada resposta que é o aprender.
A ensinabilidade própria da filosofia só se concretiza na medida em que o sentido do filosofar se compreende como exercício de pensar sobre a existência pessoal e coletiva de cada ser humano. Para tal, necessita-se de qualificação. A qualificação é importante ao exercício pedagógico, mas ela não é determinante para o professor, pois ela nunca engendra, em si, todos os elementos e momentos da prática docente. A autoridade também é fundamental, pois reflete 0 modo pelo qual o trabalho pedagógico será desenvolvido. A qualificação centraliza a questão pedagógica na discussão da instrução, autoridade e responsabilidade no estímulo à construção do conhecimento. Segundo Arendt (2005):

\section{A qualificação do professor consiste em conhecer o mundo e ser capaz de instruir os outros acerca deste, porém sua autorida- de se assenta na responsabilidade que ele assume por este mundo. (p. 239)}

Deseja-se assim abrir campo para a discussão e reflexão acerca do ensino como fenômeno da busca por aprender e discursar sobre a realidade e como também do professor de filosofia no horizonte da sua atividade docente. A abordagem que se faz aqui sobre o fenômeno educativo pensa o "jogo" da interpretação-ação. Discutir e refletir são elementos imprescindíveis ao diálogo, portanto, à comunicação. A linguagem humana é comunicação do inteligível. Desse modo, o ensino deve ser uma explanação do que pode ser compreendido e refletido. Assim, "ensinar significa fazer compreender" (Rezende, 1990, p. 54). Sendo aquilo que se revela, que vem à luz e que pode ser compreendido nesse desvelamento, o ensino (ou seja, a ação de ensinar) é um dos fenômenos que certamente nos ajuda na interpretação da funcionalidade da escola como instituição social. Desse modo, segundo Rezende (1990):

2. A aquisição desse sentido na interpretação do como é pensada seguindo a interpretação hermenêutica heideggeriana proposta para a compreensão do sentido que se imprime na análise do sentido da vida e do mundo (Heidegger, 2006). 
Ao considerar a educação um fenômeno, devemos começar por reconhecer que se trata de uma experiência profundamente humana. Em sentido forte, é mesmo uma experiência universal e exclusivamente humana: todos os homens se educam e só eles o fazem. Isto significa que a experiência da educação se torna uma das manifestações mais primitivas e típicas do fenômeno humano, em relação essencial com as outras características deste último. Tanto os indivíduos como os grupos, a família e a sociedade, a história e o mundo, estão implicados na estrutura do fenômeno educacional. Isto quer dizer que, em sua polissemia, a educação pode ser enfocada de vários pontos de vista, mas cada um deles acaba por nos remeter aos demais. (p. 46)

\section{Quem é o professor de filosofia? A sua identidade na tensão limites-possibilidades}

De um modo geral, quando se lança uma pergunta sobre o perfil de um profissional de determinada área, parece lógico que o que se procura saber é se há uma identificação entre esse profissional, como pessoa, e o trabalho, a habilidade técnica que desenvolve em relação ao que se pode considerar como um princípio, um marco referencial. Ao se tomar como referência o professor, a pergunta feita busca identificar os elementos que por si só sejam capazes de especificá-lo. Por exemplo: a pessoa do professor deve ser a de alguém que compreende o potencial transformador da educação de tal forma que assumiu a docência como habilidade profissional. Ele não é um vendedor de sonhos, é um agente transformador da história, pessoal e coletiva.

A figura de uma pessoa que condensa em si o saber, que determina os livros a serem estudados e as avaliações e, daí, todos os critérios de aprovação, ainda povoa, em muito, o imaginário dos alunos acerca do perfil do professor. Esse perfil pode ser sintetizado na ima- gem do professor sabe-e-faz-tudo. E isso é um dos fatores da crise da educação no ensino apontado por Hannah Arendt (2005):

Um professor, pensava-se, é um homem que pode simplesmente ensinar qualquer coisa; sua formação é no ensino, e não no domínio de qualquer assunto particular. Além disso, ela resultou nas últimas décadas em um grave negligenciamento da formação dos professores em suas próprias matérias, particularmente nos colégios públicos. (p. 243)

Buscando a superação da imagem sabee-faz-tudo, deve-se, inevitavelmente, buscar compreender que o que se deseja é refletir sobre o perfil do professor como docente. Portanto, seu perfil é fundamentalmente o de relação, sendo essa relação especificamente pedagógica. Partindo do referencial assumido: ser o professor aquele que assumiu a docência como sua profissão é, portanto, imprescindível que ele seja bem formado e preparado para melhor introduzir os alunos no universo de sua área de conhecimento, tanto quanto ele viabiliza o desenvolvimento da cultura como um todo. Longe de uma postura metodológica deficitária, que faz com que o professor seja obrigado a fazer aquilo que não é de sua formação, conforme Arendt (2005).

Essa ideia do professor polivalente, pela qual se pensa poder ensinar tudo, pois se acredita ser sua formação no ensino-transmissão de conteúdo, distorce a centralidade do conceito de ensinabilidade que é próprio da Filosofia. 0 caráter específico de ser uma disciplina que versa sobre o ensino e a aprendizagem dos seus próprios conceitos, em Arendt (2005), é identificado na devida apropriação do que se identifica como sendo a importância da tradição e da formação específica do professor para ensinar.

Na pontuação dessa conceituação, dois personagens emergem: o professor e o aluno; e entre eles, um elemento: o contato com as disciplinas específicas. Em toda disciplina, qual- 
quer que seja, o itinerário deve ser, com adaptações concernentes a cada área, num esquema de possibilitar o conhecimento particularizado sem esquecer o todo, o que é o saber. Essa totalização do saber, que é o desenvolvimento das capacidades cognitivas interpretativas do abstrato, de modo a torná-lo inteligível e discursivo, prescinde de uma fenomenologia do conhecimento que se caracteriza na transposição da teoria a essa forma decisiva de práxis.

No caso da filosofia e sociologia, a transposição dos conhecimentos e reflexões tem em vista, para a sala de aula, a sistematização reflexiva de questões atuais (Ministério da Educação, 2004), de modo que os problemas que se referem às pessoas e ao tempo de hoje possam ser discutidas com base em uma estrutura conceitual que emergiu de pessoas de um tempo anterior ${ }^{3}$. Esse elemento que valoriza a tradição apresentase como ponto elementar na constituição dos "marcos" para a fundamentação da autoridade do saber (Arendt, 2005). A temática da "autoridade" é explorada, pela autora, por ser elementar na análise da crise da modernidade e atinge todas as instâncias que compõem o mundo social. A falta de um marco referencial conduz a uma formação vazia, sem identidade ou história na qual se possam fundamentar as questões a serem abordadas. Assim, esclarece Arendt (2005) que

\section{[...] a autoridade só pode adquirir caráter} educacional se se admite, com os romanos, que sob todas as circunstâncias os antepassados representam o exemplo de grandeza para cada geração subsequente, que eles são maiores, por definição. (p. 161)

A crise na educação está intrinsecamente ligada à perda de referências que justifiquem o fio condutor das questões que nos "assaltam", pondo-nos sempre a refletir. Arendt (2005) afirma que

[.... [ a crise da autoridade na educação guarda a mais estreita conexão com a crise da tradição, ou seja, com a crise de nossa atitude face ao âmbito do passado. (p. 243)
A Filosofia é essa motivação inquietante de procurar compreender a realidade, que toma de assalto o filósofo, motivando-o a pensar sobre si mesmo e a realidade que o toca, estabelecendo um contato de construção de conhecimentos (1) entre ele e os outros seres humanos; (2) ele e o ambiente; e (3) entre ele e as inquietações mais profundas sobre as quais o homem há muito se debruça. São essas problemáticas que desafiam a nós no espaço do mundo e do tempo, apontando a necessidade de pensar o futuro a partir das interpretações que são feitas pelo humano e das ações que se realiza no tempo presente.

É tal intensidade de assumir-se 'filósofo' que Renata Aspis (2004) ${ }^{4}$, ao localizar o professor de filosofia no ponto de partida de toda a experiência filosófica na sala de aula, coloca-o como referência, entre os alunos, daquela pessoa que "desconstrói-se para se reconstruir, buscando encontrar as saídas filosóficas para os problemas abordados em sala” (p. 310).

0 limite à concretização da perspectiva do professor de filosofia como iniciador de experiências de reflexão e abordagem conceitual na sala de aula seria a sua não postura filosófica. Isso pode ter origem por vários motivos: déficit de integração entre os conhecimentos pedagógicos e filosóficos ou mesmo a ausência de formação em uma das áreas, o que infelizmente acontece em grande número na maioria das salas de aula, pois muitos dos profissionais que lecionam filosofia não têm a formação filosófica específica. Pode haver, ainda, um entrave ou fechamento, no caso especifico da formação filosófica, a apenas uma área do conhecimento filosófico, sem aber-

3. Sobre a importância de levar em consideração a tradição filosófica no desenvolvimento do estudo filosófico tendo em consideração a sua importância no que se refere à pertinência da reflexão sobre a prática educativa, ver especialmente Marcondes, 2004.

4. Ver especialmente o que diz respeito à atitude filosófica do professor ao buscar a solução de problemas, tendo por perspectiva a reflexão filosófica, na qual a autora tem por uma das referências o pensamento de Niestzsche, afirmando aquilo que o filósofo defende: "uma vez que se tenha encontrado a si mesmo, é preciso saber, de tempo em tempo, perder-se e depois reencontrar-se: pressuposto que se seja um pensador" (Aspis, 2004, p. 313). Assim, ela fundamenta a necessidade que ele, o professor, seja o primeiro a "alcançar este homem que está em constante transformação", a fim de abdicar da ideia de "professor como super-herói" (p. 314). 
tura a outras possibilidades de interpretação, o que inviabilizaria esse movimento de ir e vir em relação do conhecimento. Theodor Adorno (1995) argumenta que "a filosofia só faz jus a si mesma quando é mais do que uma disciplina especifica" (p. 53). Sua postura é em rechaça aos profissionais, alguns da filosofia, que consideram a sua área como o centro do mundo, esquecendo-se de refletir os problemas atuais com base na reflexão filosófica.

E isso, segundo Arendt (2005), quer dizer:

Não apenas os estudantes são efetivamente abandonados a seus próprios recursos, mas também que a fonte mais legítima da autoridade do professor, como a pessoa que, seja dada a isso a forma que se queira, sabe mais e pode fazer mais que nós mesmos, não é mais eficaz. (p. 231)

Desse limite, que se apresenta profundamente ligado ao subjetivo, decorreriam vários outros que se expressam na sala de aula, no que toca a relação ensino-aprendizagem dos alunos para com o professor e com a disciplina e do professor com a disciplina e com os alunos (no que ambas o incitam a sempre 'reaprender o aprendido').

Silvio Gallo (2008) assim afirma:

Um professor que faça esse movimento precisa assumir-se, ele mesmo, como filósofo. Como poderá convidar os alunos a fazer o movimento, mediá-los nesse processo, se ele mesmo não o fizer? (p. 9)

\section{As possibilidades nas quais se pode ensinar Filosofia}

Essas possibilidades, de um modo mais abrangente, ou a possibilidade, no pontuamento da questão da prática docente do professor com sua turma, referem-se à busca do desenvolvimento de uma metodologia que viabilize a apreensão do sentido das aulas como, para os alunos, a construção de um sentido para o estudo filosófico no contexto de uma cultura educacional prá- tico-finalista, que no estágio final do ensino médio submete alunos ao vestibular. A perspectiva adotada não quer restringir-se, ao final do processo, somente ao espaço da sala de aula. 0 que se espera é a perpetuação da reflexão filosófica nos vários incidentes da vida. 0 trabalho de Marcondes (2004), quando investiga as possibilidades e o modo de se ensinar filosofia, evidencia a necessidade de manter o equilíbrio da balança entre a história da tradição filosófica e a reflexão dos problemas atuais, pois, segundo o autor,

[...] nem todas as questões da tradição permanecem atuais, a forma do Bem, o Motor Imóvel ou o Logos Spermátikos são conceitos que possuem interesse apenas histórico, importantes para entendermos as teorias respectivamente de Platão, de Aristóteles e dos estóicos, porém, não mais diretamente relevantes para o nosso contexto. Por outro lado, os problemas que levaram Platão, Aristóteles e os estóicos à formulação desses conceitos, como a necessidade de um princípio para a ética ou a necessidade de explicarmos o movimento e a mudança, são problemas que ainda nos preocupam. (p. 60)

\section{A metodologia e o sentido para o ensino filosófico}

Uma análise proposta a partir da contribuição da filosofia ao uso do termo 'sentido' é tomada para o planejamento educacional e a prática didática que busque ressaltar a importância de sempre se pensar o porquê pela qual as ações são conduzidas. À especificação do termo sentido, recorreu-se a Comte-Sponville (2003).

0 que se pretende neste ponto não é retomar a metodologia que compõe este trabalho, mas uma tentativa de esboçar o fundamento que caracteriza a ensinabilidade que é própria da filosofia, que é o que se pode ter por método de ensino-aprendizagem de reflexão filosófica.

0 modo de interpretar o que é a filosofia nos oferece vários pontos de vista sobre esse campo do saber. Quando a ela se atribui 
uma ensinabilidade, isso quer dizer que a filosofia é uma disciplina que didaticamente se situa no conjunto da sala de aula por ser possível de ser ensinada e, à sua presença no currículo escolar, corresponde uma perspectiva formadora de consciência reflexiva acerca do fenômeno humano no espaço das ciências, como também dos 'problemas' humanos. "0 aprender é também, sempre, um aprender a conhecer" (Heidegger, 1987, p. 78). De acordo com o que foi dito, as coisas são visadas com essa designação na medida em que se pode aprender. Assim, afirma:

[...] aprender é um modo do apreender e do apropriar-se. 0 aprender é, portanto, um tomar e um apropriar-se pelo qual o uso se torna objeto de apropriação. Uma tal apropriação acontece através do próprio uso. Chamamolhes exercício. Mas o exercitar-se, novamente, é apenas o modo de aprender. (p. 77)

0 que se toma por problemas são os enunciados que dizem respeito à interpretação do mundo e do fenômeno humano que procura investigar as suas causas em si mesmas, atribuindo-lhes sentido por si mesma e, dessa forma, precisando sempre ser recolocada nos termos de sua afirmação.

0 que se põe à discussão nesse parágrafo é justamente o que a maioria dos especialistas na área de estudos do pensamento antigo coloca como sendo o fundamento pela qual a mudança de pensamento cosmológico grego provocou como sendo a origem do pensamento filosófico. A estrutura do mito dá lugar a uma nova forma de ver o mundo, que é a racional, filosófica. Jean Pierre Vernant (1990) interpreta esse momento de passagem como um momento de mudança epistemológica de modo que a leitura de mundo mítica é 'racionalizada' e passa, então, a ser interpretada como 'problemas'. Citando Cornford (1952), ele diz: "Na filosofia o mito é racionalizado" (p. 447). Sua interpretação afirma: "o mito toma a forma de um problema explicitamente formulado, o mito era uma narrativa e não a solução de um problema" (p. 448). A partir dessa 'problematização' feita pelos filósofos, conclui Vernant (1990) que "o problema constitui, na sua forma, a matéria prima da filosofia" (p. 448). De tal modo que isso se apresenta em Silvio Gallo (apud Borba, 2008) e Deleuze e Guatari (1992) ao pensarem a filosofia como disciplina: ao lidar com o pensamento filosófico, a elaboração de conceitos exige que a colocação do problema seja pensada de forma em considerar a busca não propriamente de soluções acabadas, mas de formas como deve ser encarado o problema, como nos indica Silvio Gallo (apud Borba, 2008):

Um problema nunca tem uma solução dada, mas ela depende de como se agenciam as singularidades que o compõem. Como multiplicidade, o problema é agenciamento, e pode ser articulado de inúmeras formas. 0 problema é resultado desses encontros e agenciamentos que se dão pelas vizinhanças das singularidades e, por sua vez, também produz suas possíveis soluções através desses encontros e vizinhanças. (p. 119)

Desse modo, partindo dessa compreensão que se pode ter acerca do ensino de filosofia, conforme o que Gallo e Deleuze apontam em seus textos, cabe-nos muito bem a afirmação do ensino de filosofia ser uma atitude formadora de conceitos. 0 ensino de filosofia deve privilegiar a espontaneidade do pensamento na busca, que deve ser uma fundamentação, das razões sobre as afirmações que são feitas em torno do espaço humano de onde ela emerge.

A metodologia que prescinde e justifica o ensino filosófico nas disciplinas do ensino médio deve prezar o desenvolvimento do aluno quanto à reflexão que se possa fazer da realidade, capacitando a atribuir valores, estabelecer critérios, proporcionando uma consciência solidária e comprometida com o mundo da vida, ter e discutir opiniões vislumbrando um ideal humanitário.

Tais proposições, sendo de caráter universal, correspondem ao sentido, ou seja, à 
afetividade que o saber move no ser humano, afirmando-o em sua inteligibilidade construtora do que se tem por real. Ensinar é buscar o sentido do que pode ser sentido. É uma garimpagem. Busca encontrar o que é de mais essencial em cada ser humano, fazendo-o pensar o ser-humano em sua totalidade.

0 espaço da sala de aula deve ser um espaço estético. 0 que corresponde a estético não é somente a forma, mas, sobretudo, ao modo sensibilizador como a filosofia, posta como disciplina, é apresentada. É algo profundamente relacional, pois envolve os sentidos, tanto na sensibilização como no encontro com o diferente, seja o outro diretamente ou com seu pensamento. Deleuze (2006) aponta que há uma identificação, segundo a lógica do que pode ser sentido, entre o espaço físico que acomoda os alunos e o professor no exercício da docência e o mundo em suas formas de vida mais variadas. Afirma o autor:

Há no mundo alguma coisa que força a pensar. Este algo é objeto de um encontro fundamental e não de uma recognição. 0 que é encontrado pode ser Sócrates, o templo ou o demônio. Pode ser apreendido sob tonalidades afetivas diversas, admiração, amor, ódio, dor. Mas em sua primeira característica, e sob qualquer tonalidade, ele só pode ser sentido. É assim que se opõe à recognição, pois o sensível, na recognição, nunca é o que pode ser sentido, mas o que se relaciona diretamente com os sentidos num objeto que pode ser lembrado, imaginado, concebido [...]. Aquilo que só de ser sentido sensibiliza a alma, tornaa 'perplexa', isto é, força-a a colocar um problema, como se o objeto do encontro, o signo, fosse portador de problema - como se ele suscitasse problema. (p. 203-204)

\section{O ensino de filosofia: limites e possibilidades na relação ensino- aprendizagem}

Ao longo do texto, a preocupação de fundamentar a ideia trabalhada privilegiou a identidade do professor tendo em vista a sua ação docente. Os parágrafos que antecedem esse ponto já dão indicativos de que a identidade do professor se constrói na sua relação com o ensino. De tal modo que, assim, de forma prévia, discutiu-se a ensinabilidade da filosofia.

Colocada nos termos de sua ensinabilidade, a filosofia reverbera o seu porquê de presença na sala de aula. 0 que se propõe é pensar elementos que corroborem, didaticamente, com esse ensino. Essa relação ocorre no jogo ensino-aprendizagem. Buscando a fidelidade à metodologia do trabalho que pensa a educação numa forma fenomenológica, o "jogo" ensinoaprendizagem poderá ser problematizado nas suas mais variadas formas, partindo de um princípio que é o da experiência filosófica. É a partir da experiência, seja a do professor que a possibilita, seja do aluno que a realiza na sua atividade de aprendizado, que as formas didáticas de ensino se manifestam e se põem como estratégias de viabilizar a entrada ao todo do edifício filosófico.

Como proposta, parte-se inicialmente das contribuições do pensamento de Aspis (2004), considerando que o ensino de filosofia se constrói na relação didática da sala de aula. "As aulas de filosofia como lugar de experiência filosófica são um lugar de estudo e produção filosóficos” (p. 315). 0 professor de filosofia é o provocador de reflexões individuais e em grupos, isso the exige habilidade de trabalhar didaticamente os assuntos, privilegiando os momentos de produção e reflexão individual com os momentos de desenvolvê-las a partir de um trabalho em e de grupo.

Da mesma forma como o seu trabalho se apresenta versando em habilidades de ensino por estratégias didáticas variadas, o professor também desenvolve seu trabalho na escola e fora dela, não só pela postura filosófica que deve ter, mas por manifestar interesse por refletir a realidade como um todo, assim como seu interesse pela pesquisa fundamenta ainda mais a sua prática docente, desembocando numa só atividade de forma que o seu trabalho seja 
enriquecido pela provocação e a provocação, pela pesquisa e ensino da disciplina.

A autoridade, como é pensada por Hannah Arendt, não é qualificação e sim, responsabilidade pelo mundo que o educador deve ter em sua arte de ensino-aprendizagem. Por esse motivo, o professor não é um diletante, até mesmo por que a educação como processo de desenvolvimento é um movimento árduo de reconstrução de valores. 0 educador é, então, um militante de sua perspectiva educativa que se baseia em ideias, valores e na prática pedagógica. No mundo circundante à sua atividade pedagógica, "ele é ainda modelo. Ele pratica e estuda a sua prática” (Aspis, 2004, p. 315).

$\mathrm{Na}$ relação ensino-aprendizagem, a chave de interpretação da relação didática a ser desenvolvida na sala de aula é de que alunos e professores aprendem uns com os outros e uns em relação com os outros. Cláudia Cisiane Benetti (2005) considera essa relação ao analisar as dificuldades do ensino-aprendizagem na sala de aula. Ela afirma "que o professor também aprende quando ensina, e por isso, quando utilizo (o termo) ensinar e aprender, ou ensinoaprendizagem, estou considerando tal premissa” (p. 304). As possibilidades de efetivação de uma relação ensino-aprendizagem frutífera estão no desenvolvimento da compreensão da importância do pensamento crítico de modo a ajudar no alargamento cognitivo, reflexivo, conceitual e argumentativo que o trabalho filosófico, na sala de aula, proporciona aos alunos e também ao professor. Marcondes (2004) afirma ser importante estabelecer uma continuidade entre a filosofia e a nossa vida, uma vez que certas questões que vivenciamos foram também questões dos grandes filósofos e que "o modo como as discutiram pode ser relevante para nós, pode nos ajudar a pensar por nós mesmos, mas junto com eles" (p. 65). 0 contrário seria "uma educação vazia e degenerada, ensinando sem educar” (Arendt, 2005, p. 247).

Benetti (2005) chama a atenção que esse fluxo de construção do conhecimento por meio de ensino-aprendizagem em que professor e alunos aprendem a aprender "rompem com um movimento linear de aprendizagem que insiste em se fazer presentes" (p. 311). Esse rompimento é a possibilidade mais viável de findar um distanciamento entre a reflexão, os problemas e os textos filosóficos, considerados incompreensíveis, e a vontade de pensar sobre as coisas cotidianas, envolvendo o aluno na apreensão dos problemas em que está inserido, possibilitando construir um sentido para as suas questões.

A partir de uma consideração mais abrangente, não querendo em nada suplantar as especificidades da produção intelectual de alguns teóricos aqui citados, podemos considerar que todos afirmam a necessidade de haver uma aproximação da reflexão filosófica com a vida cotidiana dos alunos. Tal possibilidade se concretizaria numa superação do distanciamento da filosofia com o cotidiano popular pela forma como a própria vida é pensada, na sua forma de compromisso com a condição humana e, no contexto da sala de aula, na forma de tratamento e desenvolvimento que a disciplina recebe na dinâmica escolar, rompendo com a perspectiva pragmática de uma ênfase incisiva ao desenvolvimento de competências e habilidades, visando, exclusivamente, às tendências de mercado ou no desenrolar do ensino de filosofia e privilegiando somente o estudo da tradição filosófica como que um historicismo filosófico.

A educação filosófica é vista como uma possibilidade de experiência formativa, por onde o educando engendra-se com o mundo. Arendt (2005) tem nesses "novos" engendrados uma esperança de possibilidade de transformação da realidade, a partir do reassumir os valores da tradição, ressignificando na atitude concreta de assumir a responsabilidade pelo mundo. Do ponto de vista da pedagogia na qual a ensinabilidade da filosofia se mostra na sala de aula, Benetti (2005) e Marcondes (2004) buscam romper com o imaginário tecnicista que ainda se tenta sustentar e justificar como sendo a finalidade da educação. As competências e habilidades estão no sentido de desenvolver o amadurecimento da reflexão e não o aprimo- 
ramento do comportamento técnico para o uso das tecnologias midiáticas industriais. Lembranos Benetti (2005) que

[...] o ato de pensar inclui em seu bojo algo que vai além das formas metódicas de direcionar o pensamento, ou seja, traz no seu contexto a construção/desconstrução/experimentação da vida. E potencializar a experimentação da vida e dos afetos advindos da relação com conceitos filosóficos que se produzem em relação com a arte, literatura, política, entre outros. (p. 306)

A autora é um tanto mais pontual quando nos ajuda a refletir sobre a condição de desenvolvimento das técnicas necessárias ao ingresso no mundo do trabalho. Afirma que somente a busca do desenvolvimento de competências e habilidades não seja o meio mais pertinente a fim de que o aluno desenvolva um consistente processo de ensino-aprendizagem. A ênfase em competências de uma forma exclusiva pode somente superficializar o sentido da dinâmica da sala de aula, que em si visa à integralidade dos conhecimentos. Desse modo, o privilégio num único modo pedagógico, ou seja, o que prioriza somente o desenvolvimento técnico, pode acabar não possibilitando, ao professor, 'focar' a questão de

[...] como permitir que, através do processo ensino-aprendizagem, o aluno conquiste o poder de estar no jogo do mundo e nele investir, resistir aos processos de alienação, opressão que o mundo atual da informação (mídia), procura nos imprimir cotidianamente. (Benetti, 2005, p. 312)

Reduzida assim a experiência filosófica que motiva o dinamismo didático das aulas de filosofia à apreensão somente da técnica exigida pelas tendências de mercado, o aluno sofre prejuízos quanto ao seu desenvolvimento integral de visão de mundo. Justamente pelo fato de privilegiar uma tendência, o pensamento reflexivo sobre o mundo, suas singularidades e pluralidade que, de um modo ou outro o constituem, não se expressam na sua forma própria de ser.

Poder-se-ia, a partir disso, apontar razões para o fundamentalismo e o pensamento totalizador que não legitima ou negligencia a justificativa de conceder validade ao diferente quando este se manifesta na sua singularidade como outra forma de 'ser', seja da coisa ou da pessoa.

Outro limite à construção de uma relação pedagógica que visa proporcionar uma efetiva relação de aprendizagem e interpretação da realidade é quando há a quebra da autoridade do professor na sala de aula, como nos afirma Arendt (2005):

0 problema da educação no mundo moderno está no fato de, por sua natureza, não poder abrir mão nem da autoridade, nem da tradição, e ser obrigada, apesar disso, a caminhar em um mundo que não é estruturado nem pela autoridade nem tampouco pela mantido coeso pela tradição. (p. 245)

Portanto, ao se argumentar acerca da experiência filosófica necessária à docência filosófica, têm-se em vista os agentes envolvidos diretamente com a dinâmica da sala de aula: professor e alunos. Se, por um lado, a experiência filosófica tem por protagonista o professor integrado com o que faz e sendo o motivador dos alunos a buscarem, por eles mesmos, o conhecimento necessário aos desafios do cotidiano, quando esse professor deixa de ser referência, a autoridade do educador e da educação escolar esvazia-se de sentido moral e pedagógico. Por outro lado, a experiência filosófica também se põe em relação ao aluno.

Do mesmo modo e constituindo a outra face da relação, de forma dialética, o aluno é protagonista de si mesmo e da forma como a experiência filosófica será intensificada na sala de aula. Essa experiência, por parte do aluno, pode ficar apenas no seu momento inicial, o de contato com a disciplina, como pode avançar em perspectivas, sendo motivadora a busca 
pelas razões que o ajudarão a repensar a sua forma de ver o mundo.

Por fim, o que nos diz respeito, e que não podemos delegar a ninguém, é o fato de que o mundo está como que 'condicionado' às manifestações de nossas decisões e transformações. A educação, como fenômeno humano e humanizador é o ponto que privilegiamos discutir e se apresenta como uma das formas de atuação sobre o mundo na maneira como expressamos se o amamos o bastante para assumirmos a responsabilidade por ele e por quem dele faz parte, com tal gesto, salvá-lo da ruína que seria inevitável se não fosse "a renovação e a vinda 'do novo' que se aponta nos jovens” (Arendt, 2005, p. 247).

De modo algum, a perspectiva é apontar um amor à materialidade do mundo em si mesma, pois sem a presença humana, seria impossivel que houvesse sequer resquícios do que temos hoje como compreensão de mundo, afinal não haveria compreensão. 0 que se defende é um amor ao mundo nas infinitas possibilidades que ele encerra na sua forma e expressão de ser o lugar humano por excelência.

\section{Considerações finais}

Toda a ação pensada experimenta a inesgotabilidade da reflexão à medida que o pensamento proposto é configurado com a realidade e a ela sempre busca abarcar. Pensar a identidade do filósofo-educador ${ }^{5}$ mostra-se na exigente tarefa de fundamentar a sua docência como prática interventora no mundo. Desse modo, o seu perfil se aponta na tensão do próprio ensino e suas possibilidades, como também está relacionado ao engajamento que a prática educativa tende a despertar.

Daí que o perfil do professor de Filosofia tecido e entretido com a sua profissão e na realidade social da qual ninguém deve buscar escapar foi, ao longo das considerações do presente texto, uma constante fuga do emolduramento a que sempre está arriscado a se comprometer. A autoridade de educar, deslocada do eixo da pos- tura sisuda e encarcerada em si mesma, de uma ação pragmática que não considera o movimento próprio do reaprender o aprendido, abre espaço a uma nova significação em que o professor é autoridade na medida em que, ele mesmo, protagoniza a experiência de fazer-se filósofo filosofando-pesquisando-lecionando. Tornandose efetivamente o filósofo-educador.

0 dito sobre os limites da realização da atividade docente e os que se põem acerca da compreensão do professor sobre si mesmo não implica, em nenhum momento, afirmar que a docência comporte limitações em sua gênese. É preciso entender a atividade do professor como um trabalho e, portanto, como uma ação construtora dos moldes humanos de agir sobre o mundo e da forma como dizer a realidade. Não considerar a educação, por princípio, como limitada, mas compreender as razões circunstanciais que a possa limitar constitui o primeiro exercício para concebê-la de um ponto de vista fenomênico. As limitações são exteriores à prática educativa, e a ela se agrega na medida em que o sujeito que a protagoniza não a repensa como perspectiva e projeção de si mesmo, como foi buscado esclarecer.

Contudo, sabendo que pode o profissional se deixar limitar, inviabilizando o fluxo da aprendizagem que a atividade docente proporciona, torna-se necessário recorrer à fundamentação dos motivos que animam a atividade docente, o ponto de partida que assim se privilegiou foi o da experiência. Um fenômeno se compreende, antes de tudo, na experiência de ser manifestação de si mesmo e ser experienciado na sua forma de mos-

\footnotetext{
5. 0 termo filósofo-educador é uma sugestão denominativa que surge nas Orientações complementares aos Parâmetros para designar o ofício do educador que trabalha na docência da filosofia no ensino médio. No texto, essa terminologia foi posta apenas nas considerações finais adrede à ideia de que todo o escrito foi uma elaboração acerca do perfil desse filósofo-educador no seu trabalho docente. É ele quem privilegia a metodologia e a forma como se vai trabalhar a disciplina na sala de aula. As linhas anteriores a essa conclusão já apontavam para isso ao se propor a pensar a ação docente no ensino de filosofia. Desse modo, que o uso desse termo não se ponha como algo que foi esquecido e somente lembrado no ultimo momento, mas que seja interpretado como uma síntese que surge nas considerações conclusivas do texto e que remetem à investigação mais aprofundada do que ele significa no contexto das orientações curriculares do Ministério da Educação.
} 
trar-se como é. Esse contrafluxo de escapada do emolduramento, muitas vezes ideológico, que quebra o fluxo do próprio processo educativo, pontua-se nas dificuldades em geral apontadas nos textos pedagógicos como um dos limites à verdadeira ensinabilidade da Filosofia.

A superação dos limites, preferencialmente, deve partir do individuo que se compreende agente protagonizador da experiência de aprender e da forma como se compreende o próprio fato de serno-mundo. É sobre a própria compreensão de si que se reconstrói as perspectivas de superação das limitações. A dinâmica de aprender é embalada na ciranda de encantar-se pelo universo.

Merleau-Ponty (1999) afirma que a verdadeira filosofia mostra-se na forma de "reaprender a ver o mundo" (p. 19), do mesmo modo que a docência de filosofia é a atividade facilitadora desse reaprendizado, e o docente com ela comprometido compreende e age conforme o fundamento do aprendizado feliz das formas mais pertinentes de reaprender a arte de ensinar, possibilitando aos alunos a experiência de saber construir e reconstruir conhecimento.

\section{Referências bibliográficas}

ADORNO. T. Educação e emancipação: os professores e a filosofia. Tradução de Wolfang Leo Maar. 3. ed. Rio de Janeiro: Paz e Terra, 1995.

ARANHA, M. G. L. Filosofia da Educação. 3. ed. São Paulo: Moderna, 2007.

ARENDT, H. Entre o passado e futuro. Tradução de Mauro W. Barbosa. São Paulo: Perspectiva, 2005.

ASPIS, R. P. L. 0 professor de filosofia: 0 ensino de filosofia no ensino médio como experiência filosófica. Cadernos Cedes, Campinas, v. 24, n. 64, p. 305-320, set./dez. 2004.

BENETTI, C. C. Dificuldades e possibilidades que constituem o ensino-aprendizagem de Filosofia nas escolas: um olhar voltado às implicações singulares na constituição do pensamento. In: RIBAS, M. A. C. (Org.). Filosofia e ensino: a filosofia na escola. ljuí: Ed. Unijuí, 2005. p. 303-316.

BORBA, S.; KOHAN, W. Filosofia, aprendizagem, experiência. Belo Horizonte: Autêntica, 2008.

COMTE-SPONVILLE, A. Dicionário filosófico. São Paulo: Martins Fontes, 2003, p. 539-543.

CORNFORD, P. Principium sapientiae: the originis of greek philosophical thought. UK: Cambridge University Press, 1952.

DELEUZE, G. Diferença e repetição. 2. ed. Rio de Janeiro: Graal, 2006.

DELEUZE, G.; GUATTARI, F. 0 que é filosofia? Rio de Janeiro: Ed. 34, 1992.

GALLO, S. Profissão professor. Revista de Filosofia. ano 1, n. 3, 2008.

HEIDEGGER, M. Que é uma coisa? Doutrina de Kant dos princípios transcendentais. Lisboa: Edições 70, 1987.

Ser e tempo. Tradução de Marcia Sá Cavalcante Schuback. Petrópolis: Vozes; Bragança Paulista: Edusf, 2006.

LIBÂNEO, J. C. Democratização da escola pública: a pedagogia crítico-social dos conteúdos. São Paulo: Loyola, 1985.

MARCONDES, D. É possivel ensinar a filosofia? E, se possível, como? In: KOHAN, W. (Org.). Filosofia: caminhos para o seu ensino. Rio de Janeiro: DP\&A, 2004. p. 54-68.

MINISTÉRIO DA EDUCAÇÃO. PCN+Ensino Médio: orientações Educacionais Complementares aos Parâmetros Curriculares Nacionais.

Parte IV - ciências humanas e suas tecnologias. Brasília/DF, 2000. Disponível em <www.mec.gov.br>. Acessado em 25/9/2008. 
MERLEAU-PONTY, M. Fenomenologia da percepção. 2. ed. São Paulo: Martins Fontes, 1999.

REZENDE, A. M. de. Concepção fenomenológica da educação. São Paulo: Cortez, 1990. (Coleção Polêmicas do Nosso Tempo, v. 38)

SILVA. S. P. A função social da escola. 2. ed. Fortaleza: Demócrito Rocha, 2004.

VERNANT, J.-P. Mito e pensamento entre os gregos: estudos de psicologia histórica. Tradução de Haiganuch Sarian. 2. ed. Rio de Janeiro: Paz e Terra, 1990.

Recebido em 05.05.09

Aprovado em 06.10 .09

Anderson Magno da Silva Pimentel, licenciado em Filosofia pelo Instituto Salesiano de Filosofia - INSAF -, Recife, é professor do ensino médio e trabalha com programas de socialização de menores. E-mail: magnopimentel@hotmail.com.

Dawson de Barros Monteiro, licenciado no INSAF, é mestrando em filosofia na Universidade Federal de Pernambuco, leciona filosofia no ensino médio e trabalha com teatro e arte-educação. 